\title{
Remote learning might be new, but how we can learn best is not
}

\section{Carrie Hanson}

McGill University, Canada

Alexander Liepins

McGill University, Canada

Keywords: learning strategies; skills development; student success; remote learning; metacognition; Covid-19.

\section{The challenge}

\section{Is learning significantly different in a remote environment?}

As part of our institution's teaching and learning center, our team provides interactive workshops for students on learning skills, metacognition, time management, learning in your second (or third) language, a wealth of different study tactics, including how and when to use them, and more. We believe anyone can learn anything and we strive to help students learn better through our programming and resources, which are grounded in research on learning capacity building and the scholarship of teaching and learning. Before terms like social distancing, remote learning, and Zoom fatigue became part of our common vocabulary namely before March 2020 - our programming was primarily centered around in-person learning experiences in an active learning classroom and facilitated by trained graduate student assistants. While we also offered a couple webinars through Zoom, they were the exception.

Just as for instructors and students, we needed to adapt when in-person support became impossible. Our more specific challenge concerned what exactly we might need to change to fit with the new reality of the remote teaching and learning context. We asked ourselves, how different, really, is remote learning from learning in general? Are we facing a crisis of content? Will the strategies that worked for students before no longer apply? After wrestling with this as 
a team, our answer was no. Apart from leveling-up on new tools and technology, and adjusting to working fully from home, we had experience with what we needed to know and do to support students' academic success in the ways that we could.

\section{The response}

\section{Shifting format while understanding our strengths}

There were several aspects to our approach. In transitioning from in-person to remote delivery, we adapted activities to make effective use of available technologies with student engagement features and leveraged these tools as mediator factors for fostering student engagement in learning (Major, 2015). We also made adjustments to our promotional materials to help clarify, communicate, and reinforce their relevance for students as remote learners. For example, one of our foundational sessions for orientation - and based around McGuire's framework for learning skills development (2015) - became 'Strategies for Remote Learning Success'. This session is designed to run for hundreds of first-year students, so the activities, such as polling, were already tailored to suit larger groups, and easily transferred over to Zoom. In another workshop entitled Study SMART, principles of effective course design (Wiggins and McTighe, 2006) were drawn upon to get students engaged in thinking about aligning their learning goals with the optimal study tactic by using annotation on shared content, rather than pen and paper. Overall, the core lessons, including goals and the message around metacognitive learning approaches that these workshops continue to champion, did not significantly change because of these adaptations. The exception to this was the addition of one slide to highlight how remote learning can put increased emphasis on the importance of autonomy in the learning process, along with the recommendation of creating an effective study space at home so long as other spaces are inaccessible.

Along with the few changes and adaptations to how we deliver our work as learning strategy practitioners, we further strove to be empathetic in our understanding of the difficult situations students found themselves in over the last year and several months. This directly informed our emphasis that they probably did not need to completely overhaul their approach to learning in a remote environment. We remained committed to instilling the importance of regularly checking in on what is and is not working and adapting where necessary as a viable 
metacognitive strategy (Winne and Hadwin, 1998) that learners can put into practice in any context.

Fortunately for our approach, students did not seem to need too much convincing.

Participation in sessions was high when compared to previous terms and feedback for these workshops was positive, which we were happy to see as consistent with expectations on our part. In our post-workshop feedback forms, respondents overwhelmingly indicated that they planned to implement something they had learned in our workshop(s). This kind of commitment to a behavioral change is what we strive for, and hope bears real fruit for the students' longer-term learning and success!

\section{Recommendations}

\section{Consistency and collaboration}

We are not saying 'remote learning isn't that different from learning in general'. Students have spent over a year being directly or indirectly reminded of the difficulties - getting and staying motivated, feeling disconnected, adapting to new ways of being in spaces; the list goes on. These are very real challenges that students continue to face. After all, so much is different, even over a year later. But when we are talking about how students can learn best, what has changed? If you need to memorise material, try some recall strategies. If you have a question, ask it - you will be better off. If you favor accountability, set a study goal or form a (virtual) study group. So, we are saying that in the face of so much upheaval in all our lives, how a student can learn best has not changed.

Our advice to others is remain committed to what you know works and explore different mediums to deliver that message to students. For us, it was transitioning to a webinar-based delivery model, supplemented with web resources that were also shared with instructors, so that they could direct their students to them. Further, our position within a teaching and learning center has continued to be critical to the outcomes of our work, since we have been able to seamlessly align our learning skills frameworks with messaging and support for instructors. Especially during the transition into and through remote teaching and learning, information was constantly evolving, but we were well-suited to keep up with it and align with 
it. So, if you are not already exploring collaborations or connections with your own institution's teaching and learning centre, we recommend this as a viable way forward, especially after experiencing the remote context.

\section{References}

Major, C. H. (2015) Teaching online: a guide to theory, research, and practice. Baltimore: Johns Hopkins University Press.

McGuire, S. Y. (2015) Teach students how to learn: strategies you can incorporate into any course to improve student metacognition, study skills, and motivation. Sterling, Virginia: Stylus Publishing, LLC.

Wiggins, G. P. and McTighe, J. (2006) Understanding by design. Upper Saddle River, N.J.: Pearson Education.

Winne, P. H. and Hadwin, A. F. (1998) 'Studying as self regulated learning', in Hacker, D. J., Dunlosky, J. and Graesser, A. C. (eds.) Metacognition in educational theory and practice. Mahwah, N.J.: L. Erlbaum Associates, pp. 277-304.

\section{Author details}

Carrie Hanson is a Skills Development Officer supporting undergraduate student learning at McGill University's Teaching and Learning Services. She received a BA from Carleton College in Minnesota in 2016 and completed her MISt from McGill University in 2019.

Alexander Liepins is the Associate Director of Student Learning and Development in Teaching and Learning Services at McGill University. He received his BA from Wisconsin Lutheran College in 2009, his MA from Memorial University of Newfoundland in 2011, and his PhD from the University of Ottawa in 2017. 